\title{
Standard compounds for establishment of in vitro test systems
}

\author{
J. G. Hengstler $\cdot$ R. Marchan $\cdot$ H. M. Bolt
}

Published online: 30 October 2014

(C) Springer-Verlag Berlin Heidelberg 2014

January 1, 2011, rang in the start of the European Union's ambitious initiative to 'replace in vivo repeated dose systemic toxicity testing.' SEURAT-1, shortened for Safety Evaluation Ultimately Replacing Animal Testing, was launched as the first step in the gargantuan FP7 research initiative to change the way that chemical safety is assessed by providing more accurate in vitro testing methods and improved predictive tools. In the present issue of the Archives of Toxicology, the editors would like to specially highlight the review article by member scientists of SEURAT-1 who comprehensively summarized SEURAT-1 liver gold standard compounds (Jennings et al. 2014). The authors have selected a particularly useful set of compounds to support the development of in vitro systems for the identification of hepatotoxic compounds, while simultaneously reviewing their known mechanisms of action. Briefly, the following principles were addressed:

- The two major mechanisms of hepatotoxicity-cytotoxicity and dysregulation of lipid metabolism.

- Groups of well-characterized compounds with alkylating and oxidizing activities as cytotoxicity can be nonspecifically induced by chemically reactive compounds.

- Standard compounds that act via highly specific cellular targets, such as inhibitors of oxidative phosphorylation or ligands of nuclear receptors. Moreover, compounds were selected that act only on single factors within lipid metabolism pathways.

- In addition to the highly specific compounds, promiscuous chemicals were also reviewed that initiate several

J. G. Hengstler $(\bowtie) \cdot$ R. Marchan $\cdot$ H. M. Bolt

Leibniz Research Centre for Working Environment and Human Factors (IfADo), Ardeystrasse 67, 44139 Dortmund, Germany

e-mail: hengstler@ifado.de molecular events leading to both cytotoxicity and compromised lipid metabolism.

The development of alternative methods to experimental animals in safety studies is at the leading edge of the current toxicological research (Seiler et al. 2011; Driessen et al. 2013; Lilienblum et al. 2008; Krug et al. 2013; Aritomi et al. (2014); Dias da Silva et al. (2013); Guo et al. (2014); Knobeloch et al. (2012)). Relevant in vitro systems for hepatotoxicity studies are of particular importance (Godoy et al. 2013; Schyschka et al. 2013; Rodrigues et al. 2013; Tolosa et al. 2013; Messner et al. 2013; Hewitt et al. 2007; Ufelmann and Schrenk 2014). Therefore, the wellchosen set of compounds that represent known mechanisms of hepatotoxicity that are presented by Jennings et al. (2014) will facilitate the systematic establishment of in vitro systems for hepatotoxicity. Nevertheless, the bar could be raised even higher in the future.

One pertinent question is how comprehensive testing of the recommended compounds brings us beyond the current state of the art. We will certainly learn whether the gold standard compounds are able to activate certain mechanisms of toxicity in the exposed cells. Specific patterns of deregulated genes or proteins will be associated with specific compounds and will provide evidence of the involved biological processes. At best, this strategy will allow hazard identification; however, toxicology requires quantitative information. To aid regulatory processes, in vitro systems must ideally predict in vivo doses that are safe and those that would result in adverse effects. Simply having the knowledge that a particular concentration (often very high) activates a characteristic mechanism of toxicity in vitro will not be sufficient.

Despite intensive research in the field of alternative methods, some challenges are still currently underestimated. For example, a response induced by a compound in 
a cultivated cell in vitro, e.g., a primary hepatocyte, is not automatically comparable to the effect caused by the same concentration used on the equivalent target cell in vivo, e.g., a hepatocyte in the liver. Although some metabolism and stress response-associated genes have shown a good in vivo/in vitro correlation (Heise et al. 2012), the culture conditions may massively alter the responsiveness of cells to chemicals, e.g., by activating anti-apoptotic mechanisms (Godoy et al. 2009, 2010). Therefore, a careful 'translation' of observations in vitro to the in vivo situation is required. Furthermore, an organism may have compensatory mechanisms that cannot become active in vitro, and specific mechanisms, such as the immune response, may be lacking in the current in vitro systems.

Progress requires a next generation of 'quantitative' gold standard compounds with accompanying data on blood concentrations in humans that are associated with increased risk of hepatotoxicity and those that are considered safe. Ideally, the concentrations in the target cells, e.g., the hepatocytes, should also be known; information that in humans is usually only obtained by PBPK modeling. Such a list of some hundreds of "quantitative gold standard compounds' with known concentration ranges of 'hepatotoxic risk' plus information on the expected mechanism would enormously support the evaluation of in vitro systems. Although the current review by Jennings and colleagues has clearly raised the bar-the hunt for gold standard compounds for evaluating in vitro systems of toxicity has only just begun.

\section{References}

Aritomi K, Ishitsuka Y, Tomishima Y, Shimizu D, Abe N, Shuto T, Irikura M, Kai H, Irie T (2014) Evaluation of three-dimensional cultured HepG2 cells in a nano culture plate system: an in vitro human model of acetaminophen hepatotoxicity. J Pharmacol Sci 124(2):218-229

Dias da Silva D, Carmo H, Lynch A, Silva E (2013) An insight into the hepatocellular death induced by amphetamines, individually and in combination: the involvement of necrosis and apoptosis. Arch Toxicol 87(12):2165-2185

Driessen M, Kienhuis AS, Pennings JL, Pronk TE, van de Brandhof EJ, Roodbergen M, Spaink HP, van de Water B, van der Ven LT (2013) Exploring the zebrafish embryo as an alternative model for the evaluation of liver toxicity by histopathology and expression profiling. Arch Toxicol 87(5):807-823

Godoy P, Hengstler JG, Ilkavets I, Meyer C, Bachmann A, Müller A, Tuschl G, Mueller SO, Dooley S (2009) Extracellular matrix modulates sensitivity of hepatocytes to fibroblastoid dedifferentiation and transforming growth factor beta-induced apoptosis. Hepatology 49(6):2031-2043

Godoy P, Schug M, Bauer A, Hengstler JG (2010) Reversible manipulation of apoptosis sensitivity in cultured hepatocytes by matrixmediated manipulation of signaling activities. Methods Mol Biol 640:139-155

Godoy P, Hewitt NJ, Albrecht U et al (2013) Recent advances in 2D and $3 \mathrm{D}$ in vitro systems using primary hepatocytes, alternative hepatocyte sources and non-parenchymal liver cells and their use in investigating mechanisms of hepatotoxicity, cell signaling and ADME. Arch Toxicol 87(8):1315-1530

Guo P, Pi H, Xu S, Zhang L, Li Y, Li M, Cao Z, Tian L, Xie J, Li R, He M, Lu Y, Liu C, Duan W, Yu Z, Zhou Z (2014) Melatonin improves mitochondrial function by promoting MT1/SIRT1/PGC-1 alpha-dependent mitochondrial biogenesis in cadmium-induced hepatotoxicity in vitro. Toxicol Sci. (Epub ahead of print)

Heise T, Schug M, Storm D, Ellinger-Ziegelbauer H, Ahr HJ, Hellwig B, Rahnenfuhrer J, Ghallab A, Guenther G, Sisnaiske J, Reif R, Godoy P, Mielke H, Gundert-Remy U, Lampen A, Oberemm A, Hengstler JG (2012) In vitro-in vivo correlation of gene expression alterations induced by liver carcinogens. Curr Med Chem 19(11):1721-1730

Hewitt NJ, Lechón MJ, Houston JB, Hallifax D, Brown HS, Maurel P, Kenna JG, Gustavsson L, Lohmann C, Skonberg C, Guillouzo A, Tuschl G, Li AP, LeCluyse E, Groothuis GM, Hengstler JG (2007) Primary hepatocytes: current understanding of the regulation of metabolic enzymes and transporter proteins, and pharmaceutical practice for the use of hepatocytes in metabolism, enzyme induction, transporter, clearance, and hepatotoxicity studies. Drug Metab Rev 39(1):159-234

Jennings P, Schwarz M, Landesmann B, Leonard MO, Wiseman JS (2014) SEURAT-1 liver gold reference compounds: a mechanism-based review. Arch Toxicol (this issue) [Epub ahead of print]. doi:10.1007/s00204-014-1389-1

Knobeloch D, Ehnert S, Schyschka L, Büchler P, Schoenberg M, Kleeff J, Thasler WE, Nussler NC, Godoy P, Hengstler J, Nussler AK (2012) Human hepatocytes: isolation, culture, and quality procedures. Methods Mol Biol 806:99-120

Krug AK, Kolde R, Gaspar JA, Rempel E et al (2013) Human embryonic stem cell-derived test systems for developmental neurotoxicity: a transcriptomics approach. Arch Toxicol 87(1):123-143

Lilienblum W, Dekant W, Foth H, Gebel T, Hengstler JG, Kahl R, Kramer PJ, Schweinfurth H, Wollin KM (2008) Alternative methods to safety studies in experimental animals: role in the risk assessment of chemicals under the new European Chemicals Legislation (REACH). Arch Toxicol 82(4):211-236

Messner S, Agarkova I, Moritz W, Kelm JM (2013) Multi-cell type human liver microtissues for hepatotoxicity testing. Arch Toxicol 87(1):209-213

Rodrigues AV, Rollison HE, Martin S, Sarda S, Schulz-Utermoehl T, Stahl S, Gustafsson F, Eakins J, Kenna JG, Wilson ID (2013) In vitro exploration of potential mechanisms of toxicity of the human hepatotoxic drug fenclozic acid. Arch Toxicol 87(8):1569-1579

Schyschka L, Sánchez JJ, Wang Z, Burkhardt B, Müller-Vieira U, Zeilinger K, Bachmann A, Nadalin S, Damm G, Nussler AK (2013) Hepatic 3D cultures but not 2D cultures preserve specific transporter activity for acetaminophen-induced hepatotoxicity. Arch Toxicol 87(8):1581-1593

Seiler A, Oelgeschläger M, Liebsch M, Pirow R, Riebeling C, Tralau T, Luch A (2011) Developmental toxicity testing in the 21st century: the sword of Damocles shattered by embryonic stem cell assays? Arch Toxicol 85(11):1361-1372

Tolosa L, Gómez-Lechón MJ, Pérez-Cataldo G, Castell JV, Donato MT (2013) HepG2 cells simultaneously expressing five P450 enzymes for the screening of hepatotoxicity: identification of bioactivable drugs and the potential mechanism of toxicity involved. Arch Toxicol 87(6):1115-1127

Ufelmann H, Schrenk D (2014) Nodularin-triggered apoptosis and hyperphosphorylation of signaling proteins in cultured rat hepatocytes. Toxicol In Vitro [Epub ahead of print]. doi:10.1016/j.tiv.2014.08.008 